\title{
A Study on Prevalence of Bovine Trypanosomosis and Associated Risk Factors in Bulen District of the Benishangul Gumuz Regional State, Western Ethiopia
}

\author{
Walkite Furgasa $^{1 *}$, Ferede Zelka ${ }^{2}$ and Birhanu Eticha ${ }^{2}$ \\ ${ }^{1}$ College of Veterinary Medicine, Wollega University, P.O.Box 395, Nekemte, Ethiopia \\ ${ }^{2}$ Benishangulgumuz Metekel zone livestock development bureau
}

Received: 14 November, 2017; Accepted: 9 March, 2018; Published: 12 March, 2018

*Corresponding author: Walkite Furgasa, College of Veterinary Medicine, Wollega University, P.O.Box 395, Nekemte, Ethiopia. Tel: +251921165829.Email: walkiteharamaya@gmail.com

\begin{abstract}
A cross sectional study was carried out from December 2016 to March, 2017 in Bulen district of the Benishangul Gumuz Region, Western Ethiopia to determine prevalence of bovine trypanosomosis and associated risk factors. Blood samples collected from $(\mathrm{n}=306)$ randomly sampled cattle (Bos indicus) was examined using parasitological (buffy coat technique) and hematological (measurement of packed cell volume) procedures. An overall, $18 / 306(5.88 \%)$ prevalence was recorded. The infection was caused mainly by Trypanosoma congolense $11 / 18(66.11 \%)$, Trypanosoma vivax $6 / 18(13.5 \%)$ and to less extent by Trypanosoma brucei $1 / 18(5.56 \%)$.The infection rate was statistically significant among difference trypanosome species $(\mathrm{P}<0.05)$. Mean packed cell volume (PCV) value of parasitaemic animals was lower $(18.21 \%+4.11)$ than aparasitaemic animals $(28.12 \%+2.67)$ and the variation was statistically significant $(\mathrm{P}>0.05)$. Higher prevalence $11 / 82(13.75 \%)$ was registered in animals with poor body condition animals when compared with animals medium 5/147(3.40\%) and good $2 / 77(2.60 \%)$ body condition and the difference was found statistically significant $(\mathrm{p}<0.05)$. In contrast, prevalence of trypanosomosis was not statistically significant across study sites, among age categories and between sex groups $(\mathrm{P}>0.05)$.To wrap up, the result of the present finding shows moderately high prevalence of trypanosomosis in the study sites indicating the need for strategic and integrated approach to control the vector and to minimize the impact of the disease in the study district.
\end{abstract}

Keywords: Bulen district; Risk factor; Trypanosomosis

\section{Introduction}

Trypanosomosis is among the well-known constraints to livestock production in Africa as it causes a serious and often fatal disease of livestock mainly in the rural poor community and rightfully considered as a root cause of poverty in the continent [1]. Most trypanosomes that are transmitted by tsetse flies inhabit many parts of the continent that extended about $15^{\circ} \mathrm{N}$ and $20^{\circ} \mathrm{S}$ of the equator, biting flies may also act as mechanical vectors of trypanosomosis [2].

Trypanosomiasis is a devastating disease of livestock caused by protozoal parasites of the genus trypanosoma that inhabits blood and other tissues of vertebrates including animals, wildlife and human [3]. It is a vector borne disease that is transmitted biologically by tsetse flies and mechanically by other biting flies [4]. It is a major constraint contributing to direct and indirect economic losses to crop and livestock production and has a significant negative impact on economic growth in many parts of the world particularly in sub-Saharan Africa [5,6].

The disease is characterized by severe anemia, weight loss, reduced productivity, infertility and abortion, with death occurring in some animals during the acute phase of the disease. Animals which survive often remain infected for several months or years, exhibiting a low level of fluctuating parasitaemia which serves as a reservoir for the disease occasionally; however, the infected animals may undergo spontaneous recovery [7].

The most important trypanosome species affecting livestock in Ethiopia are Trypanosoma congolense, Trypanosoma vivax, and Trypanosoma brucei in cattle, sheep and goats, Trypanosoma evansi in camels and Trypanosoma equiperdium in horses [5]. The influence of tsetse on African agriculture through the transmission of trypanosomosis continues to be a major constraint to the development of national economies and their achievement of self sufficiency in basic food production. The general distribution of tsetse flies is determined principally by climate and influenced by altitude, vegetation, and presence of suitable host animals [8].

Ethiopia is situated at the East end of the African tsetse belt. In Ethiopia, tsetse flies are confined to south western and north western regions between longitude $33^{\circ}$ and $38^{\circ} \mathrm{E}$ and latitiude $5^{0}$ and $12^{0} \mathrm{~N}$ that covers an area of about $22,000 \mathrm{~km}^{2}$ [9]. Tsetse infested areas lies in the low lands and also in the river valleys of Blue Nile, Baro Akobo, Didessa, Ghibe and Omo. Benishangul Gumuz is one of the five regions of Ethiopia infested with more than one species of tsetse flies. Five species of Glossina (Glossina morsitans submorsitans, G. Pallidipes, G. tachnoides, G. f. fuscipes and G. longipennis) have been registered in Ethiopia [10]. In the study region of Benishangul Gumuz regional state, four glossina 


\section{State, Western Ethiopia}

species namely, G. tachinoides, G.morsitant submorsitances, G. pallidipes and G.fuscipes were found [11]. Apart from the cyclical transmission of trypanosomosis by Glossina species, it is highly considered that mechanical transmission is a potential threat to livestock production and productivity in some parts of Ethiopia [5].

Bulen is one the seven districts of Metekel zone of the Benishangul Gumuz regional state, western Ethiopia with a serious problem of trypanosomosis. Controlling this economically important disease in this area could have a number of benefits to improve the livelihood of the poor people of the district by increasing milk, meat, surplus capital from the sale of livestock and livestock products and improving the availability of draft power (oxen).Although the disease is one of the main obstacles of livestock production and productivity in the district, the prevalence and situation of the disease was assessed only once by and no further strategic and participatory control measures of have been made and the problem of the disease is still continuing in the district [12]. Therefore, the present studies were designed with the following objectives:

- To determine the prevalence of bovine trypanosomosis in the district;

- To identify associated risk factors for the occurrence of the disease;

- To forward possible prevention and control measures against the disease in the district.

\section{Materials and Methods}

\section{Study Area Period}

The study was conducted from December 2016 to March, 2017 in Bulen district of Metekel Zone, Benishangul Gumuz Regional State, Western Ethiopia to determine prevalence of bovine trypanosomosis and associated risk factors. Bulen district is located $550 \mathrm{~km}$ away from Addis Ababa. The area is located at $9^{0} 00^{\prime \prime}$ to $11^{0} 07^{\prime \prime} \mathrm{N}$ latitude and $35^{\circ} 45^{\prime \prime}$ to $36^{\circ} 07^{\prime \prime} \mathrm{E}$ longitude. It was carried out in six Kebeles here after called sites namely: Mata, Addis Alem, Chilanko, Bekuji, Dobi and Badore. The district has 19 kebeles covering an area of $2858 \mathrm{~km}^{2}$ with human population of 57567 [13]. It has an altitude range of 900-2300meter above sea level. Its annual average temperature is $28.75^{\circ} \mathrm{c}\left(23.5-34^{\circ} \mathrm{c}\right)$ and its rain fall range is $900-1500 \mathrm{~mm}$. The livelihood of the people in the district largely depends on mixed livestock and crop production having livestock population of 102,904 cattle, 16,192 sheep, 48,034 goats and 9,281equines [13].

\section{Study Design and Study Animals}

Cross sectional study design was used. A local zebu cattle (Bos indicus), that are mainly kept under an extensive husbandry system grazing the communally owned pasture land throughout the year were randomly sampled. They grazed together during the day time and returned to their individual owner's farmstead each evening. The body condition of each of the study cattle was scored as good, medium and poor [14]. Similarly, their age was determined based on principles as young ( $<2$ years old), matured
(2-5 years old) and adult (> 5 years old) (annex 2) [15].

\section{Sampling Methods and Sampling Size Determination}

The type of sampling methods was simple random sampling to establish the prevalence and associated risk factors of trypanosome infection in the study area. The desired sample size was determined using the formula given by [16].

$$
\mathrm{n}=\frac{1.96^{2}\left(\mathrm{p}_{\exp }\left(1-\mathrm{p}_{\exp }\right)\right)}{\mathrm{d}^{2}}
$$

Where: $\mathrm{n}=$ require sample size

$$
\begin{aligned}
& P_{\text {exp }}=\text { expected prevalence } \\
& d=\text { desire absolute precision } \\
& 1.96^{2}=\text { z-value for the } 95 \% \text { confidence level }
\end{aligned}
$$

The prevalence of bovine trypanosomosis in Bulen district was reported to be $5.6 \%$ by [10]. Therefore, an expected prevalence of $5.6 \%$ was taken to estimate the sample size. Taking $95 \%$ confidence level, $5 \%$ precision and $5.6 \%$ expected prevalence 81 animals were needed to study the prevalence. However, 306 cattle were sampled to increase the level of precision and randomness.

\section{Study Methodology \\ Packed Cell Volume (PCV) Determination}

Blood samples were obtained by puncturing the marginal ear vein with lancet and collected directly into a pair of heparinised capillary tubes. The tubes were then sealed at one end with crystal seal. PCV was measured in a micro-Haematocrit centrifuge (Hermmle Labortechnik, type Z, Germany). The capillary tubes were placed in microhaematocrit centrifuge with sealed end outer most. Then the tube was loaded symmetrically to ensure good balance. After screwing the rotary cover and closing the centrifuge lid, the samples were allowed to centrifuge at 12,000 rpm for 5 minutes. After centrifugation, the capillary tubes were placed in a Haematocrit reader. The length of the packed red blood cells column is expressed as a percentage of the total volume of blood. Animals with PCV less than $24 \%$ were considered to be anemic [17].

\section{Buffy coat technique}

Heparinized microhaematocrit capillary tubes, containing blood samples were centrifuged for 5 minutes at 12,000 rpm. After the centrifugation, trypanosomes were usually found in or just above the buffy coat layer. The capillary tube was cut using a diamond tipped pen $1 \mathrm{~mm}$ below the buffy coat to include the upper most layers of the red blood cells and $3 \mathrm{~mm}$ above to include the plasma. The content of the capillary tube was expressed on to a glass slide, and covered with cover slip. The slide was examined under $\mathrm{x} 40$ objective and $\mathrm{x} 10$ eye piece for movement of parasite (Murray and Dexter, 1988)(annex 3).Trypanosome species were identified according to their morphological descriptions as well as movement in wet film preparations [17]. 


\section{Data Analysis}

During the study period, data were collected using the sample collection format and entered into Microsoft Excel. Hematological and parasitological data were managed very carefully. Then, the data from the Microsoft excel sheet were processed and analyzed by using a statistical soft ware program (STATA 7). Chi square was used to compare the prevalence of trypanosomosis in different variables and to determine the relationship between variables and the result. Data collected on PCV values were analyzed by ANOVA to compare the mean PCV values of parasitaemic animals against that of aparasitaemic animals. In all cases the difference between parameters were tested for significance at probability level of 0.05 or less. The prevalence of cattle trypanosomosis was calculated as the number of parasitologically positive animals examined by buffy coat method to the total animals examined [16].

\section{Result}

\section{Prevalence of Trypanosomes Infection}

Out of the total animals examined, 18/306(5.88 \%) were infected with trypanosomes. The trypanosome species responsible for the infection were T.congolense, T.vivax and T.brucei.The proportional prevalence of each species of trypanosome was $11 / 18(61.11 \%)$ for T. congolense,6/18(33.33 $\%$ ) for T. vivax, 1/18(5.56\%) for T. brucei and the proportional prevalence of trypanosome species was found to be statistically significant $(P<0.05)$ (Table1).

Table 1: Prevalence of single and mixed infection of cattle with trypanosomes in Bulen district

\begin{tabular}{|c|c|c|c|c|}
\hline Trypanosomes & $\begin{array}{c}\text { No. } \\
\text { positive }\end{array}$ & $\begin{array}{c}\text { Prevalence } \\
\text { (\%) }\end{array}$ & $\mathbf{X}^{2}$ & (P-value) \\
\hline T. congolense & 11 & 66.11 & 182.5627 & 0 \\
\hline T. vivax & 6 & 33.33 & & \\
\hline T. brucei & 1 & 5.56 & & \\
\hline Total & $\mathbf{1 8}$ & $\mathbf{1 0 0}$ & & \\
\hline
\end{tabular}

\section{Haematological Survey Results}

The mean PCV values for all examined animals were $24.48 \pm$ 3.34 SD. However, the mean PCV for non infected animals were $28.12 \pm 2.67$ SD and the mean PCV value of the infected animals was $18.21 \pm 4.11 \mathrm{SD}$ and the association was found significant between non infected and infected animals $(\mathrm{P}<0.05)$ (table 2 ). The overall prevalence of animals with anemia in the study district was 165/306 (53.92\%). The prevalence of animals with anemia was statically significant in trypanosome infected cattle $(88.89 \%)$ than in non-infected cattle $(11.11 \%)(P<0.05)$ (Table 2).

\section{Trypanosomosis and Associated Risks}

The highest and the lowest prevalence of trypanosomosis were recorded in Badore 7/61 (11.48\%) and Mata 2/60 (3.33\%) study sites respectively and no trypanosome positive animal was registered at Chilanko study site. There was no significant association among the study sites and trypanosome infection in the study district $(\mathrm{p}>0.05)$ (Table 3 ).

The Prevalence of trypanosomosis varies in both sexes; the infection in female is higher 13/164 (7.93\%) than male 5/142 $(3.52 \%)$ however, the association was not statistically significant $(\mathrm{P}>0.05)$ (table 3 ). In the present study animals examined were categorized in different age groups as $<2$ years, 2-5 years and $>5$ years. Out of the total sampled animals, 67, 107 and 132, were $<2$ years, $2-5$ years and $>5$ years old respectively and the prevalence was found to be $3 / 67(4.48 \%)$ for animals $<2$ years, $5 / 107$ (4.67 \%) for animals 2-5 years and 10/132(7.58 \%) for tested animals $>5$ years old and the difference in the prevalence was not statistically significant ( $p>0.05$ ) (Table 3).

Similarly, during the study, animals were categorized in to differentbody conditions as good, medium and poor. From the total 306 animals examined 79,147 and 80, were registered as good, medium and poor body condition respectively and out of which 2/77 (2.60 \%), $5 / 147$ (3.40\%), and 11/82(13.75\%) prevalence of trypanosomosis were recorded for animals with good, medium

Table 2: Mean PCV comparison of parasitaemic and aparasitaemic animals in Bulen district

\begin{tabular}{|c|c|c|c|c|c|c|}
\hline Status & Frequency & Mean PCV (\%) & SD & Overall PCV & $\mathbf{X}^{2}$ & p-value \\
\hline Parasitaemic & 18 & 18.21 & 4.11 & 327.78 & & \\
\hline Aparasitaemic & 288 & 28.12 & 2.67 & 8098.56 & 9.4117 & 0.002 \\
\hline Total & 306 & 24.48 & 3.34 & 7490.88 & & \\
\hline
\end{tabular}

and poor body condition respectively. Trypanosome infection and body condition scores of study animals were found statistically significant $(\mathrm{p}<0.05)$ (Table 3$)$.

\section{Discussion}

The present study revealed an overall 18/306(5.88 \%) prevalence of trypanosomosis caused by different species of trypanosomes. This finding was in agreement with the previous studies conducted by whose finding showed $6 \%$ prevalence in his study on prevalence of bovine trypanosomosis and host related risk factors in Jawi district of the Amhara region, south west of Ethiopia, whose report showed $5.58 \%$ prevalence in their study on trypanosomosis in Cattle Population of jawi district of the Benishangul Gumuz Region, Western Ethiopia and who reported $5.43 \%$ prevalence in their study on prevalence of bovine trypanosomosis and Apparent Density of Tsetse and Other Biting Flies in Bullen district of the Benishagul Gumuz region, western Ethiopia $[18,19,20]$. Although it was slightly lower, it was found to be consistent with the former results reported by who reported an overall prevalence of $7.81 \%$ in Guto Gida district of Eastern 

State, Western Ethiopia

Table 3: prevalence of bovine trypanosomosis and its association with various risk factors in Bulen district

\begin{tabular}{|c|c|c|c|c|c|}
\hline Risk factors & No. examined & No. positive & Prevalence (\%) & $x^{2}$ & p-value \\
\hline \multicolumn{6}{|l|}{ Sites } \\
\hline Mata & 60 & 2 & 3.33 & 6.9073 & \\
\hline Addis Alem & 55 & 4 & 7.27 & & 0.228 \\
\hline Bekuji & 47 & 3 & 6.38 & & \\
\hline Chilanko & 38 & 0 & 0 & & \\
\hline Dobi & 45 & 2 & 4.44 & & \\
\hline Badore & 61 & 7 & 11.48 & & \\
\hline Total & 306 & 18 & 5.88 & & \\
\hline \multicolumn{6}{|l|}{ Sex } \\
\hline Female & 164 & 13 & 7.93 & & \\
\hline Male & 142 & 5 & 3.52 & & \\
\hline Total & 306 & 18 & 5.88 & 2.6682 & 0.102 \\
\hline \multicolumn{6}{|l|}{ Age(years) } \\
\hline$<2$ & 67 & 3 & 4.48 & & \\
\hline $5-\mathrm{Feb}$ & 107 & 5 & 4.67 & & \\
\hline$>5$ & 132 & 10 & 7.58 & & \\
\hline Total & 306 & 18 & 5.88 & 1.2052 & 0.547 \\
\hline \multicolumn{6}{|l|}{ Body conditions } \\
\hline Good & 77 & 2 & 2.6 & & \\
\hline Medium & 147 & 5 & 3.4 & & \\
\hline Poor & 82 & 11 & 13.75 & & \\
\hline Total & 306 & 18 & 5.88 & 12.1809 & 0.002 \\
\hline
\end{tabular}

Wollega Zone of Oromia region, whose finding was $8.55 \%$ in Sasiga and Diga districts of East Wollega Zone of Oromia Region and who reported an overall prevalence of $7.81 \%$ in Wemberma district of West Gojjam Zone of the Amhara Region, Northwest Ethiopia. Incontrast, the present finding was much lower when compared with previous reports whose report indicated $26.3 \%$ prevalence in and around Asossa district of the Benishangul Gumuz region, Western Ethiopia, whose finding showed an overall prevalence of $24.7 \%$ in Mao-Komo special district of the Benishangul Gumuz region, Western Ethiopia, whose finding revealed an overall prevalence of $19.53 \%$ in their study on Prevalence of Cattle Trypanosomosis, Apparent vector density and Associated Risk Factors in Debate District, Western Ethiopia and whose report showed an overall prevalence of $16.10 \%$ in their study on Prevalence of Bovine Trypanosomosis and Associated Risks in Mao Komo Special District of the Benishagulgumuz Region, Western Ethiopia [21,22,23,24,25,26,27]. The relatively low prevalence of trypanosomosis in the present study might be due to the differences in agro-ecology and climatic conditions of the localities.

Of the total cases registered, $11 / 18(66.11 \%), 6 / 18(33.33 \%)$ and $1 / 18(5.56 \%)$ were found to be caused by T. congolense, $T$. Vivax, T. brucei respectively. This indicates statistically significant difference among the distribution of trypanosome species $(\mathrm{p}<$ 0.05 ). This finding was in consistent with the previous finding of who reported $63.64 \%, 27.27 \%$, and $9 \%$ for trypanosome species of $\mathrm{T}$ [28]. congolense, T. vivax, and T. brucei respectively During their study in Dale Wabera district of Kellem Wollega Zone of Oromia Region, Western Ethiopia, similarly, it was in concordance with whose finding showed proportional prevalence of $T$. congolense to be $53.33 \%$, T. vivax $30 \%$ and T. brucei $16.66 \%$ in their study on Prevalence of Bovine Trypanasomosis in Guto Gida District of East Wollega Zone of Oromia Region, Western Ethiopia [21].

Among the study sites, the highest and the lowest prevalence of trypanosomosis were recorded in Badore PA 7/61(1148\%) and MataPA 2/60(3.33\%) respectively and no trypanosome infection was registered in Chilanko study site. However there was no significant difference $(p>0.05)$ in the prevalence of trypanosomosis and the study sites. This finding was in agreement with the finding of in their study on Bovine Trypanosomosis and Apparent Vector density in Bambasi District of Benishangul Gumuz Region, Western Ethiopia, in their study on Post Control Survey on Prevalence of Bovine Trypanosomosis and Vector Distribution in Ameya District, South West Shewa, Ethiopia According to there is difference in prevalence of trypanosomosis 


\section{State, Western Ethiopia}

in different study sites and the difference among kebeles/study sites/is due to difference in vegetation cover; reproduction and development of flies are highly influenced by climatic conditions [29,30 31].

The prevalence of trypanosome infection was higher in female animals 13/163(7.93\%) than males 5/142(3.52\%), although it was not statistically significant $(\mathrm{p}>0.05)$. This finding was in agreement with the previous findings of found higher infection rate in females animals than males in some parts of Ethiopia. The possible reason for this difference might be due to physiological difference between female and male animals because female animals are more exposed to physiological stresses than males [32].

Higher prevalence of trypanosomosis was observed $11 / 80(13.75 \%)$ in animals with poor body condition when compared with animals with medium 5/147 (3.40\%) and good $2 / 77(2.60 \%)$ body condition and the association was found statistically significant $(\mathrm{p}<0.05)$ and this finding was in agreement with study carried out by and who reported higher trypanosome infection rate in animals with poor body condition than in animals with good and medium body condition. Similarly, higher prevalence was registered in animals aged $>$ years $10 / 132(7.58$ $\%$ ) when compared with animals 2-5 years5/107(4.68 \%) and $<2$ years $3 / 67(4.48 \%)$ and statistically significant associations were not observed $(\mathrm{p}>0.05)$ and this finding was in agreement with previous worker who reported higher prevalence of trypanosome infection in adult animals than young in their study on Prevalence of bovine trypanosomosis in Chilga District, Northwest Ethiopia [20,33,34,35].

The overall mean PCV value of all examined animals was $(24.48 \% \pm 3.34$ SD). The mean PCV of non infected cattle was higher $(28.12 \% \pm 2.67 \mathrm{SD})$ than that of infected animals $(18.21 \%$ $\pm 4.11 \%$ ) and the association was statistically significant. This finding was in agreement with the previous works and who reported lower mean PCV value in infected animals than non infected ones [27,36]. Similarly, (Daud and Molalegne, 2011) and reported lower mean PCV value in infected than in the noninfected animals [25,37].

\section{Conclusion and Recommendation}

The findings of the present study revealed the importance of trypanosmosis and its contribution to hampering the product, productivity, work performance and general health status of cattle in the district. The most widely distributed and dominant species of trypanosome in the study sites are T. congolense $(66.11 \%)$ followed by T. vivax (33.33\%) and T. brucei (5.56\%) that were mainly transmitted by tsetse flies (G.m.submorsitanas, G. fuscipes and G. pallidipes) and other biting flies. Significant association was not observed within study sites, sex category and age groups of study animals ( $p>0.05$ ) while there was statistically significant association among body condition scores and PCV values of study animals and trypanosome infection $(\mathrm{P}<0.05)$. These all revealed that Bulen district is favorable for the successive breeding of tsetse and other biting flies that play a major role in the transmission of trypanosomes to susceptible hosts.
Therefore, the based on the above conclusion, the following recommendations were forwarded:

1. All available, acceptable and conventional technologies should be used effectively to control and eradicate the parasites and the vectors;

2. Creation of awareness to the rural communities with the relation of parasite and vector and their impact on live stock production should be considered by the concerned body;

3. Epidemiological studies should be conducted in the area in order to decide control strategies and determine its economic impact at large.

4. Laboratory facility and skilled veterinary professionals should be fulfilled in the clinic and animal health post to avoid tentative diagnosis which is a challenge for drug resistance.

\section{Acknowledgements}

We would like to thanks our appreciation to Bedele Regional laboratory, Parasitology laboratory and personnel working in the lab for their cooperation during the study.

\section{Conflict of Interests}

The authors declare that they have no competing interest.

\section{References}

1. Vreysen M J B. Prospects for area-wide integrated control of tsetse flies (Diptera Glossinidae) and trypanosomosis in Sub-Saharan Africa. Revista delasociedad Entomologic Argentina. 2006;65:1-21.

2. Urquhart G M, Armour J, Duncan J L, Dunn A M, Jenning F M. veterinary parasitology. 2nd ed. London: Black well science. 1996;213-216.

3. Bal M S, Sharma A, Ashuma, Bath B K, Kaur P, Singla L D. Detection and management of latent infection of Trypanosoma evansi in a cattle herd. Ind. J. Anim. Res. 2014:48(1):31-37.

4. OIE. Manual of standards for diagnostic tests and vaccines for terrestrial animals, 6th ed. Paris. 2009; 813-2008.

5. Abebe G. Current situation of Trypanosomosis. In: review article on: Trypanosomosis in Ethiopia. Ethiop. J Biol Sci. 2005;4:75-121.

6. Cecchi G, Mattioli RC, Slingenbergh J, de la Rocque S. Land cover and tsetse fly distributions in sub-Saharan Africa. Med. Vet. Entom., 2008;22(4):364-373.

7. Nantulyia V M. Immunological approaches to use in the control of animal trypanosomosis, Tropical, Medicine Parasitology. 1986; 40:168-173.

8. Leak S G A. Tsetse biology and ecology: their role in the epidemiology and control of trypanosomosis. CAB International.Wallingford (UK). 1998; $152-210$.

9. NTTICC. National Tsetse and Trypanosomosis Investigation and control center. Report for the period 7th June 2003 to 6th July 2004. Bedele, Ethiopia. 2004;21-24.

10. Keno M. The current situation of tsetse and trypanosomosis in Ethiopia, Ministry of Agriculture and Rural Development, Veterinary service department, in proceeding of 28th meeting of International Scientific Council for Trypanosomosis Research and Control. 2005. 
11. ARVDSMSL. Asossa, Regional Veterinary Diagnostic, Surveillance, Monitoring and Study Laboratory annual report. 2015.

12. Asmamaw A, Yesmashewa W, Kafaylew C, Gashaw B, Etsegenet T, et al. Epidemiology of Cattle Trypanosomosis and Its Vector Density in Bullen District. 2016; 2(6). doi:10.15406/ijvv.2016.02.00050

13. CSA. Central Statistical agency, Federal Democratic Republic of Ethiopia, Agricultural Sample Survey volume 2. 573 Statistical bulletin.2004;39-49.

14. Nicholson M J, Butterworth M H. A guide to condition scoring of zebu cattle. ICCA, Addis Ababa, Ethiopia. 1986.

15. De-Lahunta A, Habel R E. Teeth. Applied veterinary Anatomy. USA. W. B. Sounders. Company. 1986; 4-16.

16. Thrusfield M. Veterinary Epidemiology. 3rd ed., UK, Blackwell Science Ltd. 2007;233-250.

17. OIE. "Standardized techniques for the diagnosis of tsetse transmitted trypanosomosis," in OIE Terrestrial Manual. Rome, Italy. 2008:49.

18. Belete A. Study on the prevalence of bovine trypanosomosis in Jawi district of Awi Zone of Amhara region; DVM thesis, Wollo University, unpuplished. 2014.

19. Asmamaw A, Getachew D. Trypanosomosis in Cattle Population of Pawe District of Benishangul Gumuz Regional State, Western

Ethiopia: Anemia, Vector Density and Associated Risks. European Journal of Applied Sciences. 2016; 8(3):60-66. doi: 10.7537/ marsrsj08031609.

20. Lelisa K, Damena D, Kedir M, Feyera T. Prevalence of Bovine Trypanosomosis and Apparent Density of Tsetse and Other Biting Flies in Mandura District, Northwest Ethiopia. J Veterinar Sci Technol. 2015;6(3):229. doi:10.4172/2157-7579.1000229

21. Gupta M P, Kumar H, Singla L D.Trypanosomiasis concurrent to tuberculosis in black bucks. Ind. Veter. J. 2009;86(7):727-728.

22. Tefese W, Melaku A, Fentahun T. Prevalence of bovine trypanosomosis and its vectors in two districts of East Wollega Zone, Ethiopia. Onderstepoort Journal of Veterinary Research. 2012; 79(1):385.

23. Yehunie B, Wudu T, Nuria Y, Sefinew A. Prevalence of bovine trypanosomosis in Wemberma district of West Gojjam zone, North West Ethiopia. Ethiop. Vet. J. 2012;16(2):41-48.

24. Shemelis M, Addis M, Fromsa A.Study on the Prevalence of Major Trypanosomes Affecting Bovine in Tsetse Infested Asossa District of Benishangul Gumuz Regional State, Western Ethiopia. Global Veterinaria. 2011;7(4):330-336.

25. Daud A, Molalegne B. Epidemiological study of Bovine Trypanosmosis in Mao-komo Special District, Benishangul Gumuz Regional State, Western Ethiopia. G lobal Veterinaria. 2011;6:402-408.
26. Birhanu E, Asmamaw A. Prevalence of Cattle Trypanosomosis, Apparent vector density and Associated Risk Factors in Dibate District, Western Ethiopia. Biomedicine and Nursing. 2016;2(4):3239. doi:10.7537/marsbnj020416.14

27.Zelalem W, Birhanu E, Dawit T, Teshome K, Kebede G, Nuraddis I A Study on Prevalence of Bovine Trypanosomosis and Associated Risks in Mao Komo Special District of the Benishagulgumuz Regional State, Western Ethiopia. European Journal of Biological Sciences. 2017;9(2):85-92. doi: 10.5829/idosi.ejbs.2017.85.92

28. Biyazen H, Duguma R, Asaye M. Trypanosomosis, Its Risk Factors, and Anaemia in Cattle Population of Dale Wabera District of Kellem Wollega Zone,Western Ethiopia. Journal of Veterinary Medicine. 2014.

29. Asmamaw A, Mengistu G. Prevalence of Bovine trypanosomosis and Apparent Vector density in Bambasi District of Benishangul Gumuz Regional State, Western Ethiopia. Ethiop Vet. J. 2016;16(2): 41-48. doi:10.7537/marsrsj080716.05

30. Firaol T, Bizunesh M, Rajeeb K R, Waktole T. Post Control Survey on Prevalence of Bovine Trypanosomosis and Vector Distribution in Ameya District, South West Shewa, Ethiopia. Global Journal of Medical research: k Interdisciplinary. 2014;14(3).

31. Adale E, Yasine A. Prevalence of bovine trypanosomiasis in Wolaita Zone Kindo Koish District of Ethiopia. Afr. J. Agr. Res.2013; 8(49):63836387.

32. Feyissa B, Samson A, Mihreteab B. Bovine Trypanosomiasis in Selected Villages of Humbo District, Southern Ethiopia. Glob. Veterinaria. 2011;7(2):192-198.

33.Zewdu S, Dessie A. Prevalence of bovine trypanosomosis in Chilga District, Northwest Ethiopia: Using Aldehyde and Parasitological tests; Academia Journal of Microbiology Research. 2016;4(4):72-77. doi: 10.15413/ajmr.2016.0108

34. Teka W, Terefa D, Wondimu A. Prevalence study of bovine trypanosomiasis and tsetse density in selected villages of Arbaminch, Ethiopia. J. Vet. Med. Anim. Health. 2012;4(3):36-41.

35. Ayana M, Tesfaheywet Z, Getnet F. A cross-sectional study on the prevalence bovine trypanosomiasis in Amhara region, Northwest Ethiopia. Livestock Res. Rural Dev. 2012;24(8).

36. Bayisa K, Getachew D, Tadele T. Bovine Trypanosomosis in Asossa District, Benishangul Gumuz Regional State, Western Ethiopia: Prevalence and Associated Risk Factors, European Journal of Applied Sciences.2015;7(4): 171-175.doi: 10.5829/idosi. ejas.2015.7.4.101128.

37. Molalegne B, Yshitila A, Asmamaw A. Prevalence of Bovine trypanosomosis in Selected Areas of Jabi Tehenan District, West Gojjam of Amhara Regional State, North western Ethiopia Global Veterinaria. 2010;5(5):243-247. 